\title{
MS35-01 | Synthons: Through the Looking-Glass, and What We Have Yet to Find
}

\section{THERE}

Bucar, Dejan-Kresimir (University College London, London, GBR)

This presentation will critically evaluate the concepts, theories, and ideas underpinning modern crystal engineering efforts, with a view to stimulating a constructive, community-wide conversation about the current state of the art [1]. Some of our recent efforts to further develop existing guidelines for the design of molecular cocrystals and solid solutions will also be discussed, along with a brief description of an alternative and underused method for the preparation of novel cocrystals [2].

[1] M. K. Corpinot, D.-K. Bučar, Cryst. Growth Des.2019, 19, 1426-1453.

[2] S. J. Diez, M. D. Eddleston, M. Arhangelskis, M. Milbled, M. J. Müller, A. D.Bond, D.-K. Bučar, W. Jones, Cryst. Growth Des.2018, 18, 3263-3268. 